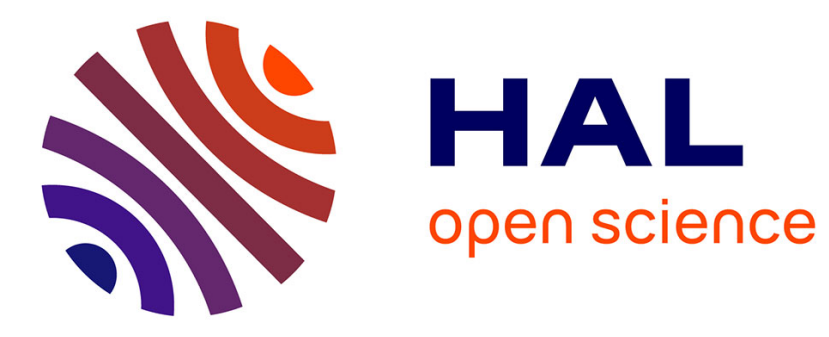

\title{
Single-walled carbon-nanotube saturable absorber assisted Kerr-lens mode-locked Tm:MgWO 4 laser
}

Li Wang, Weidong Chen, Yongguang Zhao, Yicheng Wang, Zhongben Pan, Haifeng Lin, Ge Zhang, Lizhen Zhang, Zhoubin Lin, Ji Eun Bae, et al.

\section{- To cite this version:}

Li Wang, Weidong Chen, Yongguang Zhao, Yicheng Wang, Zhongben Pan, et al.. Single-walled carbon-nanotube saturable absorber assisted Kerr-lens mode-locked Tm:MgWO 4 laser. Optics Letters, 2020, 45 (22), pp.6142. 10.1364/OL.411288 . hal-03345989

\author{
HAL Id: hal-03345989 \\ https://hal.science/hal-03345989
}

Submitted on 12 Oct 2021

HAL is a multi-disciplinary open access archive for the deposit and dissemination of scientific research documents, whether they are published or not. The documents may come from teaching and research institutions in France or abroad, or from public or private research centers.
L'archive ouverte pluridisciplinaire HAL, est destinée au dépôt et à la diffusion de documents scientifiques de niveau recherche, publiés ou non, émanant des établissements d'enseignement et de recherche français ou étrangers, des laboratoires publics ou privés. 


\title{
Single-walled carbon-nanotube saturable absorber assisted Kerr-lens mode-locked $\mathrm{Tm}: \mathrm{MgWO}_{4}$ laser
}

\author{
Li Wang, ${ }^{1}$ Weidong Chen,,${ }^{1,2,}{ }^{*}$ Yongguang ZhaO, ${ }^{1}$ Yicheng Wang, ${ }^{1,6}$ \\ Zhongben Pan, ${ }^{1}$ Haifeng Lin, ${ }^{2}$ Ge Zhang, ${ }^{2}$ Lizhen Zhang, ${ }^{2}$ ZHOUbin Lin, $^{2}$ \\ Ji Eun Bae, ${ }^{3}$ Tae Gwan Park, ${ }^{3}$ Fabian Rotermund, ${ }^{3}$ Pavel loiko, ${ }^{4}$ \\ Xavier Mateos, ${ }^{5}$ Mark Mero, ${ }^{1}$ Uwe Griebner, ${ }^{1}$ and Valentin Petrov ${ }^{1}$
}

\author{
${ }^{1}$ Max Born Institute for Nonlinear Optics and Short Pulse Spectroscopy, Max-Born-Str. 2a, 12489 Berlin, Germany \\ ${ }^{2}$ Key Laboratory of Optoelectronic Materials Chemistry and Physics, Fujian Institute of Research on the Structure of Matter, Chinese Academy \\ of Sciences, Fuzhou, 350002 Fujian, China \\ ${ }^{3}$ Department of Physics, Korea Advanced Institute of Science and Technology (KAIST), 34141 Daejeon, Korea \\ ${ }^{4}$ Centre de Recherche sur les lons, les Matériaux et la Photonique (CIMAP), UMR 6252 CEA-CNRS-ENSICAEN, Université de Caen, 6 Boulevard \\ du Maréchal Juin, 14050 Caen Cedex 4, France \\ ${ }^{5}$ Universitat Rovira i Virgili (URV), Física i Cristal-lografia de Materials i Nanomaterials (FiCMA-FiCNA), 43007 Tarragona, Spain \\ ${ }^{6}$ yicheng.wang@ruhr-uni-bochum.de \\ *Corresponding author: chenweidong@fjirsm.ac.cn
}

Received XX Month XXXX; revised XX Month, XXXX; accepted XX Month XXXX; posted XX Month XXXX (Doc. ID XXXXX); published XX Month XXXX

\begin{abstract}
We demonstrate sub-100 fs Kerr-lens mode-locking of a Tm:MgWO ${ }_{4}$ laser emitting at $\sim 2 \mu \mathrm{m}$ assisted by a singlewalled carbon nanotube saturable absorber. A maximum average output power of $100 \mathrm{~mW}$ is achieved with a pulse duration of $89 \mathrm{fs}$ at a pulse repetition rate of $\sim 86 \mathrm{MHz}$. The shortest pulse duration derived from frequency-resolved optical gating amounts to $76 \mathrm{fs}$ at $2037 \mathrm{~nm}$ corresponding to nearly bandwidth-limited pulses. To the best of our knowledge, these are the shortest pulses generated from any Tm-doped tungstate crystal and the first report on saturable absorber assisted Kerr-lens mode-locking of a Tm laser at $\sim 2 \mu \mathrm{m}$. (c) 2020 Optical Society of America.
\end{abstract}

http://dx.doi.org/10.1364/OL.99.099999

A rapid progress in the generation of sub-100 fs ultrashort pulses from thulium $\left(\mathrm{Tm}^{3+}\right)$ solid-state lasers in the 2- $\mu \mathrm{m}$ spectral range started after the first demonstration of a $\mathrm{Tm}: \mathrm{MgWO}_{4}$ laser modelocked (ML) by a graphene-based saturable absorber (SA) in 2017. Pulses as short as $86 \mathrm{fs}$ at $2017 \mathrm{~nm}$ with an average output power of $39 \mathrm{~mW}$ were obtained directly from an ML oscillator [1]. Subsequently, slightly shorter (84fs and $78 \mathrm{fs}$ ) pulses were generated using Tm-doped disordered garnet crystals Tm:CNNGG and Tm:CLNGG, and single-walled carbon-nanotubes based SAs (SWCNT-SAs) [2, 3]. After extra-cavity chirp compensation, pulses as short as $72 \mathrm{fs}$ were obtained from a Kerr-lens ML Tm: $\mathrm{Sc}_{2} \mathrm{O}_{3}$ laser [4]. Sub-10 optical cycle pulse generation at $\sim 2 \mu \mathrm{m}$ was first demonstrated in 2018 based on a $\mathrm{Tm}:(\mathrm{Lu}, \mathrm{Sc})_{2} \mathrm{O}_{3}$ "mixed" sesquioxide ceramic laser ML by a semiconductor saturable absorber mirror (SESAM) [5]. Further improvement in pulse shortening benefited from the usage of a SWCNT-SA in a ML $\mathrm{Tm}:(\mathrm{Lu}, \mathrm{Y})_{2} \mathrm{O}_{3}$ "mixed" ceramic laser generating $57 \mathrm{fs}$ pulses with an average output power of $63 \mathrm{~mW} \mathrm{[6].} \mathrm{The} \mathrm{implementation} \mathrm{of}$ broadband chirped mirrors (CMs) exhibiting high reflectivity over $330 \mathrm{~nm}$ and almost flat group delay dispersion (GDD) over more than $300 \mathrm{~nm}$ for dispersion management together with selected host materials possessing broad and relatively smooth gain spectra in combination with natural emission above $2.0 \mu \mathrm{m}$ [7] to overcome the problems related to water vapor absorption below $2.0 \mu \mathrm{m}$ was instrumental for the above achievements.

Tungstates and molybdates represent a huge class of anisotropic crystalline materials with different crystallographic symmetries and offer polymorphism [8]. Most popular as laser hosts is the family of the monoclinic potassium rare-earth double tungstates since they contain optically passive ions that can be easily substituted by optically active trivalent lanthanides such as $\mathrm{Tm}^{3+}$. In contrast to the cubic sesquioxides or garnets, the emission in such materials is naturally polarized. Tm: $\mathrm{KLu}\left(\mathrm{WO}_{4}\right)_{2}$ was employed in the first steady-state passively ML Tm-laser with a SWCNT-SA to generate $\sim 10$ ps pulses at $\sim 1.95 \mu$ m [9]. The main challenge for achieving stable femtosecond ML operation with such crystals comes from the fact that the free-running emission wavelengths is well below $2.0 \mu \mathrm{m}$, in the range of strong and structured water vapor absorption. A spectrally selective element can be used to shift the central wavelength but this will narrow the spectrum. Thus, 386-fs pulses at $2030 \mathrm{~nm}$ were achieved from a 


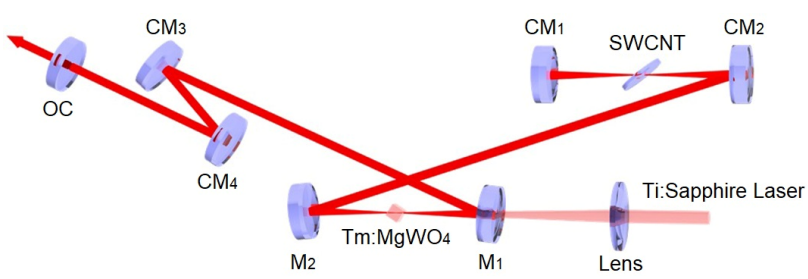

Fig. 1. Experimental arrangement of the ML Tm:MgWO 4 laser, Lens: pump focusing lens; $\mathrm{M}_{1}-\mathrm{M}_{2}$ : concave dichroic mirrors; $\mathrm{CM}_{1}-\mathrm{CM}_{4}$, chirped mirrors; OC: output coupler.

SESAM ML Tm:KY(WO $)_{2}$ laser [10] and 141-fs pulses from a SWCNT-SA ML Tm:KLu( $\left(\mathrm{WO}_{4}\right)_{2}$ laser at $2037 \mathrm{~nm}$ [11].

$\mathrm{Tm}^{3+}: \mathrm{MgWO}_{4}$ (shortly Tm:MgW) is a representative of another family of monotungstate/monomolybdate crystals which exhibit the same monoclinic symmetry. It features (i) high thermal conductivity $(\sim 8.7 \mathrm{~W} / \mathrm{mK})$, which is beneficial for high power operation, (ii) extremely broad and smooth gain cross-section spectra supporting sub-100 fs pulses which is related to crystal field distortions when substituting the divalent $\mathrm{Mg}^{2+}$ host ions by $\mathrm{Tm}^{3+}$, (iii) free-running emission wavelength above $2 \mu \mathrm{m}$, which overcomes the above mentioned problem of water vapor absorption causing ML instabilities in fs-pulse operation even without $\mathrm{N}_{2}$ purging, and (iv) polarized absorption and emission, just as Tm:KLu($\left(\mathrm{WO}_{4}\right)_{2}$, which offers more flexibility in pumping and spectral bandwidth utilization $[12,13]$. The superior thermooptical and spectroscopic properties motivated us to explore the potential of the Tm:MgW crystal for Kerr-lens ML (KLM) operation. To the best of our knowledge, so far there have been no reports on KLM operation based on a Tm-doped tungstate crystal operating at $2 \mu \mathrm{m}$. With the implementation of a SWCNT-SA for starting and stabilizing the KLM operation, in this work we achieve a pulse duration as short as 76 fs from the Tm:MgW oscillator. This result represents the shortest pulse duration ever achieved from any Tm-doped tungstate crystal and the first report on SA assisted KLM operation of a Tm laser at $\sim 2 \mu \mathrm{m}$.

Laser operation was studied in an linear astigmatically compensated X-shaped cavity as shown in Fig. 1. The laser gain medium was an $\mathrm{N}_{g}$-cut Tm:MgW crystal grown by the top-seeded solution growth method [14]. It had a measured $\mathrm{Tm}^{3+}$ concentration of 0.89 at. $\%$, an aperture of $4 \times 4 \mathrm{~mm}^{2}$ and was 3$\mathrm{mm}$ thick. The crystal was mounted in a water-cooled $\mathrm{Cu}$ holder (coolant temperature: $14^{\circ} \mathrm{C}$ ) and placed at Brewster's angle to select the highest gain of the $N_{m}$ polarization, between two dichroic folding mirrors $\mathrm{M}_{1}$ and $\mathrm{M}_{2}(\mathrm{RoC}=-100 \mathrm{~mm})$. A second beam waist was created by using two curved chirped mirrors $\mathrm{CM}_{1}(\mathrm{RoC}=-$ $50 \mathrm{~mm}$ ) and $\mathrm{CM}_{2}$ (RoC $=-150 \mathrm{~mm}$ ). In continuous wave (CW) operation, with the SA removed, the other cavity arm contained only a plane-wedged output coupler (OC). The cavity mode inside the laser crystal was estimated by using the ABCD formalism giving a waist radius of 30 and $56 \mu \mathrm{m}$ in the sagittal and tangential planes, respectively. A narrow-linewidth CW Ti:Sapphire laser tuned to $800 \mathrm{~nm}$ was employed as a pump source with polarization parallel to the $N_{m}$ crystal axis. The pump beam was focused into the Tm:MgW crystal using a lens (focal length: $f=$ $70 \mathrm{~mm}$ ) yielding a radius of $30 \mu \mathrm{m}$. A maximum output power of $577 \mathrm{~mW}$ was obtained in the CW laser regime with $3 \%$ transmission of the $\mathrm{OC}$ at an absorbed pump power of $1.67 \mathrm{~W}$ corresponding to a slope efficiency of $35.5 \%$. The experimentally measured single-pass pump absorption under lasing conditions
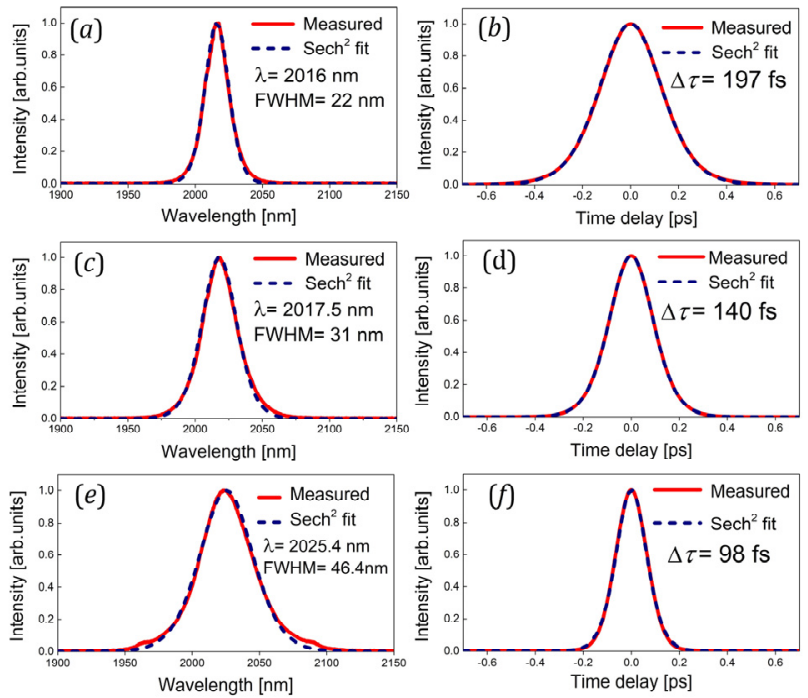

Fig. 2. Optical spectra (a, c and e) and the corresponding autocorrelation traces (b, d and f) of the ML Tm:MgW laser $\left(T_{\mathrm{OC}}=1.5 \%\right)$.

slightly varied with the OC $(0.5 \%$ - $5 \%)$ between $36 \%$ and $39 \%$. A total round-trip resonator loss of $\delta=0.85 \%$ (reabsorption losses excluded) was estimated with the Caird analysis by fitting the measured slope efficiency as a function of the OC reflectivity [15].

For ML operation, the SWCNT-SA was placed at Brewster's angle at the second beam waist between $\mathrm{CM}_{1}$ and $\mathrm{CM}_{2}$ for achieving soliton ML operation. The estimated radius of this second beam waist was 37 and $52 \mu \mathrm{m}$ in the sagittal and tangential planes, respectively. The SWCNTs were fabricated by the arcdischarge method and were deposited on a $1 \mathrm{~mm}$-thick uncoated quartz substrate acting as a transmission-type SA. Typical characteristics include a non-saturable loss of $\sim 1 \%$, a modulation depth of less than $0.5 \%$, and a saturation fluence around $10 \mu \mathrm{J} / \mathrm{cm}^{2}$ $[7,16]$. Two additional flat $\mathrm{CMs}, \mathrm{CM}_{3}$ and $\mathrm{CM}_{4}$ were introduced in the other cavity arm for balancing the intracavity material dispersion and the induced self-phase modulation (SPM) during ML operation. All CMs used for intracavity dispersion management exhibited a GDD of $-125 \mathrm{fs}^{2}$ per bounce.

In a first series of ML experiments the transition from SWCNTSA ML to KLM is demonstrated. By employing a 1.5\% OC, stable and self-starting fs ML operation was initiated by the SWCNT-SA at an absorbed pump power of $816 \mathrm{~mW}$ through its efficient bleaching. The 7 bounces of the laser beam on the CMs with a total round-trip GDD of $-887 \mathrm{fs}^{2}$ ensured optimum performance with soliton-like pulses [see Fig. 2(a) and (b)]. The nearly perfect sech ${ }^{2}$ fitting of both the measured ML spectrum and the autocorrelation trace yielded a pulse duration of $197 \mathrm{fs}$ at $2016 \mathrm{~nm}$ with a spectral full width at half maximum (FWHM) of $22 \mathrm{~nm}$ and an average output power of $50 \mathrm{~mW}$. In order to introduce an efficient softaperture Kerr-lens effect, we gradually enlarged the laser mode size inside the Tm:MgW crystal by varying the separation between the pump mirror $\mathrm{M}_{1}$ and the folding mirror $\mathrm{M}_{2}$ while keeping the same absorbed pump power [17]. A significant broadening of the ML spectra was observed when translating the folding mirror $\mathrm{M}_{2}$ by several hundreds of micrometers away from the pump mirror $\mathrm{M}_{1}$. In Fig. 2(a), (c) and (e), the FWHM of the ML spectra increased from 22 to $46.4 \mathrm{~nm}$. The corresponding measured pulse duration decreased from 197 to $98 \mathrm{fs}$. The calculated time-bandwidth 


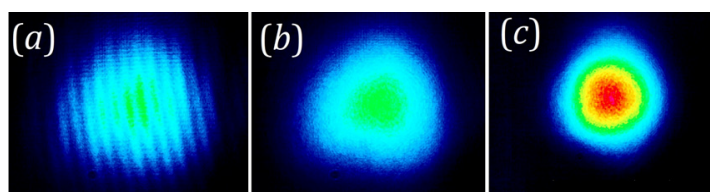

Fig. 3. Mode-locked Tm:MgW laser - transition of SWCNT-SA ML to KLM by changing the mirror separation $\mathrm{M}_{1}-\mathrm{M}_{2}$ (Toc $\left.=1.5 \%\right)$. Far-field beam profiles: (a) CW; (b) SWCNTs-SA ML; and (c) KML.

product (TBP) remained almost unchanged, amounting to 0.32 , 0.32 and 0.332 in the three cases. The central wavelength experienced a red-shift by $\sim 9.4 \mathrm{~nm}$, i.e., from 2016 to $2025.4 \mathrm{~nm}$. Pulse shortening and the wavelength shift indicates that KLM became the dominant pulse shaping mechanism and the SWCNTSA played the role as starter and stabilizer of the ML Tm:MgW laser. With the assistance of the SWCNT-SA, KLM operation of the Tm:MgW laser could be achieved without pushing the resonator to its stability edges to fulfill the requirement of a maximized selfamplitude modulation. The maximum average output power for KLM operation with $98 \mathrm{fs}$ pulse duration was $72 \mathrm{~mW}$ at a pulse repetition rate of $\sim 86 \mathrm{MHz}$. The corresponding on-axis intracavity laser intensity on the Tm:MgW crystal was calculated to be $\sim 35.2 \mathrm{GW} / \mathrm{cm}^{2}$.
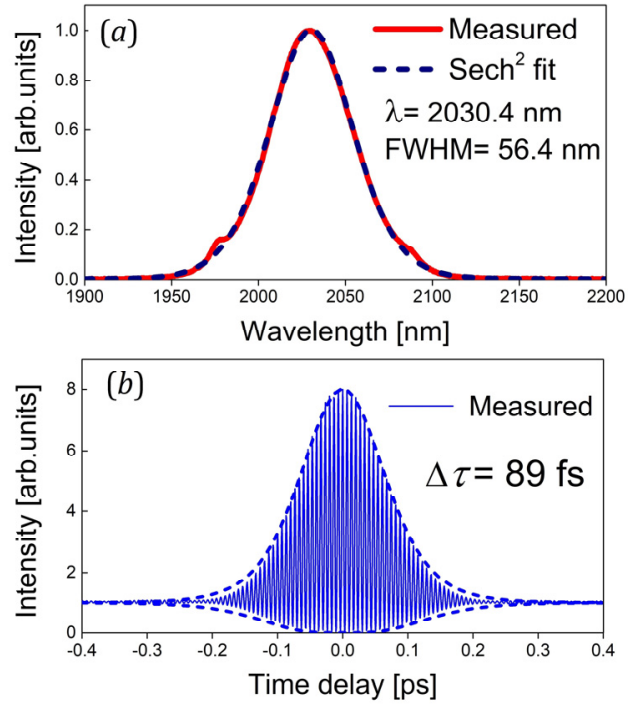

Fig. 4. (a) Optical spectrum and (b) interferometric autocorrelation trace of the mode-locked $\mathrm{Tm}$ : $\mathrm{MgW}$ laser with $\mathrm{T}_{\mathrm{oc}}=1.5 \%$.

Soft-aperture KLM operation was further confirmed by monitoring the output beam profile, as shown in Fig. 3. A mid-IR Camera (DataRay, WinCamD) was placed at $\sim 1.6 \mathrm{~m}$ away from the OC to measure the far-field beam profiles. In CW operation, the beam in the far-field had a diameter of $6.29 \times 6.01 \mathrm{~mm}^{2}$, as shown in Fig. 3(a). The strong interference fringes observed originated from reflections at the front and rear surfaces of a neutral density filter placed in front of the mid-IR camera. When mode-locking was initiated by the SWCNT-SA without soft-aperture Kerr-lens effect [cf. Fig. 2(a) and (b)], the interference fringes disappeared from the measured far-field beam profile due to the reduced coherence length which is shorter than the pulse duration, Fig. 3(b). The measured diameter of the beam in the far-field
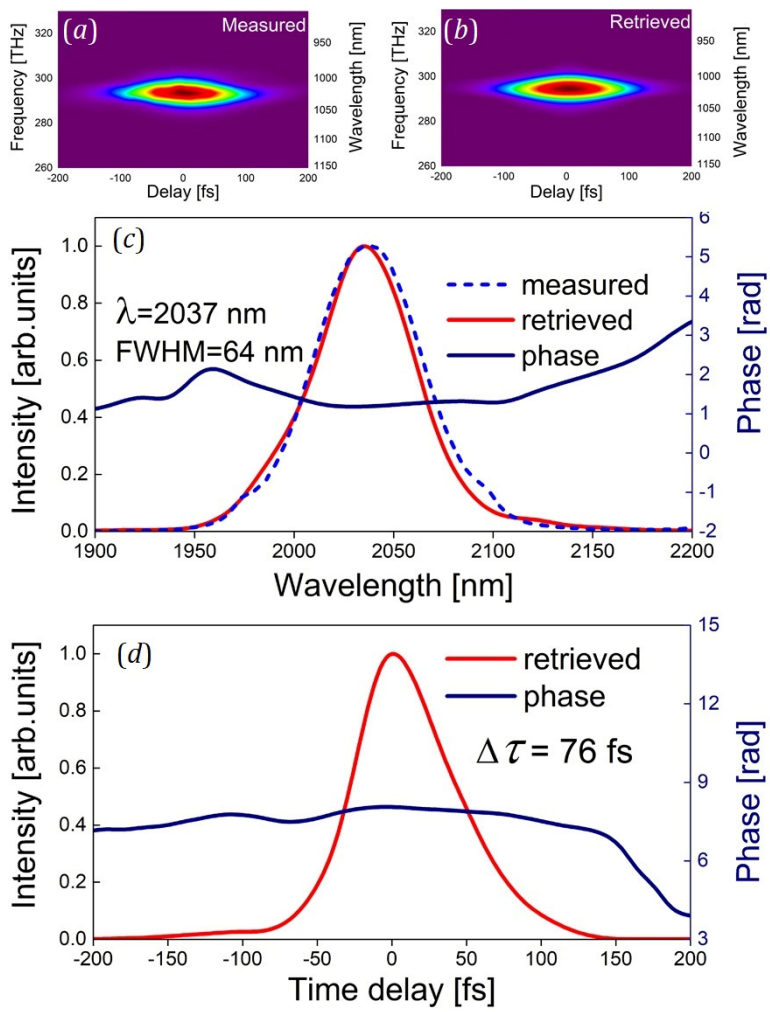

Fig. 5. (a) Measured and (b) retrieved SHG-FROG spectrogram of the Kerr-lens ML Tm:MgW laser (Toc=0.5\%). (c) Measured optical spectrum (dashed line) together with the retrieved one and the spectral phase. (d) Retrieved temporal intensity profile and the associated temporal phase.

amounted to $6.37 \times 6.02 \mathrm{~mm}^{2}$. The nearly identical sizes of the farfield beam profiles in CW and SWCNT-SA ML operation indicates a mostly absence of KLM. The transition to dominating soft-aperture KLM, i.e., strong self-focussing inside the Tm:MgW crystal with soft-aperture Kerr-lens effect [cf. Figs. 2(e) and (f)] is confirmed by shrinking of the diameter in the far-field beam profile to $4.96 \times 4.67 \mathrm{~mm}^{2}$, Fig. 3(c).

The second series of experiments aimed at the generation of the shortest pulses in the regime with dominating KLM. Scaling the absorbed pump power leads to shorter pulse. At an absorbed pump power of $1.12 \mathrm{~W}$, the center wavelength of the KLM spectrum shifted to $2030.4 \mathrm{~nm}$ with a sech $^{2}$ fitted FWHM of $56.4 \mathrm{~nm}$, as can be seen from Fig. 4(a). The measured interferometric autocorrelation trace gave a pulse duration of $89 \mathrm{fs}$, as shown in Fig. 4(b). The average output power increased to $100 \mathrm{~mW}$ at $86 \mathrm{MHz}$. The corresponding on-axis intracavity laser intensity on the Tm:MgW crystal increased to $\sim 53.8 \mathrm{GW} / \mathrm{cm}^{2}$.

The pulse duration could be further shortened by reducing the OC transmission to $0.5 \%$ at the expense of the average output power. Pulses as short as 80 fs were directly emitted from the selfstarting KLM Tm:MgW oscillator with a measured spectral FWHM of $64.4 \mathrm{~nm}$. The average output power in this case amounted to $35 \mathrm{~mW}$ for $881 \mathrm{~mW}$ of absorbed pump power. The slightly chirped pulses with a TBP of 0.372 were extra-cavity chirp compensated with a 3-mm-thick ZnS ceramic plate. The shortest pulses were characterization by second-harmonic generation (SHG) frequencyresolved optical gating (FROG) using a 1-mm-thick type-I $\mathrm{LiNbO}_{3}$ 

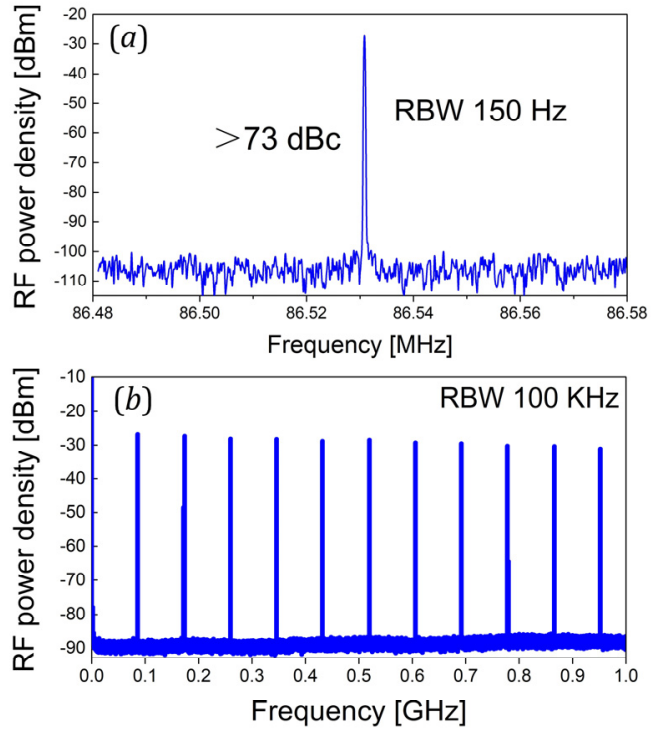

Fig. 6. Measured radio-frequency spectrum of the Kerr-lens modelocked Tm:MgW laser: (a) Fundamental beat note at $86.5 \mathrm{MHz}$ measured with a resolution bandwidth (RBW) of $150 \mathrm{~Hz}$ and (b) its harmonics on a 1-GHz span, measured with a RBW of $100 \mathrm{kHz}$.

crystal. The results are shown in Fig. 5. The measured SHG-FROG spectrogram was reconstructed with an error of 0.0054 on a $128 \times 128$ grid, Fig. 5(a) and (b). The independently measured ML spectrum agree well with the retrieved FROG spectrum yielding a spectral FWHM of $64 \mathrm{~nm}$ and a central wavelength of $2037 \mathrm{~nm}$, as shown in Fig. 5(c). After extra-cavity chirp compensation, pulses as short as $76 \mathrm{fs}$ were obtained, see the retrieved temporal profile in Fig. 5(d). The corresponding TBP of 0.354 indicates nearly bandwidth limited pulses.

The CWML pulse train was characterized by a radio-frequency analyzer. Figures 6 (a) and (b) show the fundamental beat note at $\sim 86.5 \mathrm{MHz}$ with a signal-to-noise ratio above $73 \mathrm{dBc}$ and a1-GHzwide span, both confirming the ultimate stability of the ML laser for the shortest pulse operation.

In conclusion, we realized saturable absorber assisted Kerr-lens mode-locking of a Tm solid-state laser at $\sim 2 \mu \mathrm{m}$. With the help of a SWCNT-SA, Kerr-lens ML operation of the Tm:MgW laser does not require any critical cavity alignment or pushing the resonator to the stability limits, in contrast to pure Kerr-lens mode-locking. The maximum average output power of $100 \mathrm{~mW}$ was obtained for a pulse duration of $89 \mathrm{fs}$. The shortest pulse duration of $76 \mathrm{fs}$ was be achieved after extra-cavity linear chirp compensation eliminating the residual chirp resulting from imperfect intracavity GDD compensation related $t$ othe stepwise GDD management using chirp mirrors.

Funding. National Natural Science Foundation of China (61975208, 51761135115, 61575199, 61850410533, 52072351); Deutsche Forschungsgemeinschaft (PE 607/14-1); Laserlab-Europe (654148); Natural Science Foundation of Jiangsu Province (BK20190104); Sino-German Scientist Cooperation and Exchanges Mobility Programme (M-0040); China Academy of Engineering Physics (CAEP) (YZJJLX2018005); Fund of Key Laboratory of Optoelectronic Materials Chemistry and Physics; Chinese Academy of Sciences (2008DP173016); National
Research Foundation of Korea (2020R1A4A2002828) and China Scholarship Council (CSC) (201704910363).

Acknowledgment. Y. Zhao acknowledges financial support from the Alexander von Humboldt Foundation through a Humboldt fellowship.

Disclosures. The authors declare no conflicts of interest

\section{References}

1. Y. Wang, W. Chen, M. Mero, L. Zhang, H. Lin, Z. Lin, G. Zhang, F. Rotermund, Y. J. Cho, P. Loiko, X. Mateos, U. Griebner, and V. Petrov, Opt. Lett. 42, 3076 (2017).

2. Z. Pan, Y. Wang, Y. Zhao, H. Yuan, X. Dai, H. Cai, J. E. Bae, S. Y. Choi, F. Rotermund, X. Mateos, J. M. Serres, P. Loiko, U. Griebner, and V. Petrov, Photon. Res. 6, 800 (2018).

3. Y. Wang, Y. Zhao, Z. Pan, J. E. Bae, S. Y. Choi, F. Rotermund, P. Loiko, J. M. Serres, X. Mateos, H. Yu, H. Zhang, M. Mero, U. Griebner, and V. Petrov, Opt. Lett. 43, 4268 (2018).

4. A. Suzuki, C. Kränkel, and M. Tokurakawa, Appl. Phys. Express 13, 052007 (2020).

5. Y. Wang, W. Jing, P. Loiko, Y. Zhao, H. Huang, X. Mateos, S. Suomalainen, A. Härkönen, M. Guina, U. Griebner, and V. Petrov, Opt. Express 26, 10299 (2018).

6. Y. Zhao, L. Wang, Y. Wang, J. Zhang, P. Liu, X. Xu, Y. Liu, D. Shen, J. E. Bae, T. G. Park, F. Rotermund, X. Mateos, P. Loiko, Z. Wang, X. Xu, J. Xu, M. Mero, U. Griebner, V. Petrov, and W. Chen, Opt. Lett. 45, 459 (2020).

7. V. Petrov, Y. Wang, W. Chen, Z. Pan, Y. Zhao, L. Wang, M. Mero, S. Y. Choi, F. Rotermund, W. B. Cho, W. Jing, H. Huang, H. Yuan, H. Cai, L. Zhang, Z. Lin, P. Loiko, X. Mateos, X. Xu, J. Xu, H. Yu, H. Zhang, S. Suomalainen, M. Guina, A. Härkönen, and U. Griebner, Proc. SPIE 11209, $112094 G$ (2019).

8. V. K. Trunov, V. A. Efremov, and Yu. A. Velikodnyi, 23, Nauka, Leningrad (1986).

9. W. B. Cho, A. Schmidt, J. H. Yim, S. Y. Choi, S. Lee, F. Rotermund, U. Griebner, G. Steinmeyer, V. Petrov, X. Mateos, M. C. Pujol, J. J. Carvajal, M. Aguilo, and F. Diaz, Opt. Express 17, 11007 (2009).

10. A. A. Lagatsky, S. Calvez, J. A. Gupta, V. E. Kisel, N. V. Kuleshov, C. T. A. Brown, M. D. Dawson, and W. Sibbett, Opt. Express 19, 9995 (2011).

11. A. Schmidt, S. Y. Choi, D. I. Yeom, F. Rotermund, X. Mateos, M. Segura, F. Diaz, V. Petrov, and U. Griebner, Appl. Phys. Express 5 (2012).

12. P. Loiko, J. M. Serres, X. Mateos, M. Aguilo, F. Diaz, L. Z. Zhang, Z. B. Lin, H. F. Lin, G. Zhang, K. Yumashev, V. Petrov, U. Griebner, Y. C. Wang, S. Y. Choi, F. Rotermund, and W. D. Chen, Opt. Lett. 42, 1177 (2017).

13. P. Loiko, Y. Wang, J. M. Serres, X. Mateos, M. Aguiló, F. Díaz, L. Zhang, Z. Lin, H. Lin, G. Zhang, E. Vilejshikova, E. Dunina, A. Kornienko, L. Fomicheva, V. Petrov, U. Griebner, and W. Chen, J. Alloys Compd. 763, 581 (2018).

14. L. Zhang, H. Lin, G. Zhang, X. Mateos, J. M. Serres, M. Aguiló, F. Díaz, U. Griebner, V. Petrov, Y. Wang, P. Loiko, E. Vilejshikova, K. Yumashev, Z. Lin, and W. Chen, Opt. Express 25, 3682 (2017).

15. J. A. Caird, S. A. Payne, P. R. Staber, A. J. Ramponi, L. L. Chase, and W. F. Krupke, IEEE J. Quantum Electron. 24, 1077 (1988).

16. W. B. Cho, J. H. Yim, S. Y. Choi, S. Lee, A. Schmidt, G. Steinmeyer, U. Griebner, V. Petrov, D. I. Yeom, K. Kim, and F. Rotermund, Adv. Funct. Mater. 20, 1937 (2010).

17. T. Brabec, C. Spielmann, P. F. Curley, and F. Krausz, Opt.s Lett. 17, 1292 (1992). 


\section{References}

1. Y. Wang, W. Chen, M. Mero, L. Zhang, H. Lin, Z. Lin, G. Zhang, F. Rotermund, Y. J. Cho, P. Loiko, X. Mateos, U. Griebner, and V. Petrov, "Sub100 fs Tm: $\mathrm{MgWO}_{4}$ laser at $2017 \mathrm{~nm}$ mode locked by a graphene saturable absorber," Optics Letters 42, 3076-3079 (2017).

2. Z. Pan, Y. Wang, Y. Zhao, H. Yuan, X. Dai, H. Cai, J. E. Bae, S. Y. Choi, F. Rotermund, X. Mateos, J. M. Serres, P. Loiko, U. Griebner, and V. Petrov, "Generation of 84-fs pulses from a mode-locked Tm:CNNGG disordered garnet crystal laser," Photon. Res. 6, 800-804 (2018).

3. Y. Wang, Y. Zhao, Z. Pan, J. E. Bae, S. Y. Choi, F. Rotermund, P. Loiko, J. M. Serres, X. Mateos, H. Yu, H. Zhang, M. Mero, U. Griebner, and V. Petrov, "78 fs SWCNT-SA mode-locked Tm:CLNGG disordered garnet crystal laser at 2017 nm," Optics Letters 43, 4268-4271 (2018).

4. A. Suzuki, C. Kränkel, and M. Tokurakawa, "High quality-factor Kerr-lens mode-locked $\mathrm{Tm}: \mathrm{Sc}_{2} \mathrm{O}_{3}$ single crystal laser with anomalous spectral broadening," Applied Physics Express 13, 052007 (2020).

5. Y. Wang, W. Jing, P. Loiko, Y. Zhao, H. Huang, X. Mateos, S. Suomalainen, A. Härkönen, M. Guina, U. Griebner, and V. Petrov, "Sub-10 optical-cycle passively mode-locked $\mathrm{Tm}:\left(\mathrm{Lu}_{2 / 3} \mathrm{Sc}_{1 / 3}\right)_{2} \mathrm{O}_{3}$ ceramic laser at 2 $\mu \mathrm{m}, "$ Optics Express 26, 10299-10304 (2018).

6. Y. Zhao, L. Wang, Y. Wang, J. Zhang, P. Liu, X. Xu, Y. Liu, D. Shen, J. E. Bae, T. G. Park, F. Rotermund, X. Mateos, P. Loiko, Z. Wang, X. Xu, J. $\mathrm{Xu}, \mathrm{M}$. Mero, U. Griebner, V. Petrov, and W. Chen, "SWCNT-SA modelocked $\mathrm{Tm}: \mathrm{LuYO}_{3}$ ceramic laser delivering 8-optical-cycle pulses at $2.05 \mu \mathrm{m}$," Optics Letters 45, 459-462 (2020).

7. V. Petrov, Y. Wang, W. Chen, Z. Pan, Y. Zhao, L. Wang, M. Mero, S. Y. Choi, F. Rotermund, W. B. Cho, W. Jing, H. Huang, H. Yuan, H. Cai, L. Zhang, Z. Lin, P. Loiko, X. Mateos, X. Xu, J. Xu, H. Yu, H. Zhang, S.

Suomalainen, M. Guina, A. Härkönen, and U. Griebner, Sub-100-fs bulk solid-state lasers near 2-micron Proc. SPIE 11209, 112094G (2019).

8. V. K. Trunov, V. A. Efremov, and Yu. A. Velikodnyi, Crystal Chemistry and Characteristics of Double Molybdates and Tungstates [in Russian], 23 Nauka, Leningrad (1986).

9. W. B. Cho, A. Schmidt, J. H. Yim, S. Y. Choi, S. Lee, F. Rotermund, U. Griebner, G. Steinmeyer, V. Petrov, X. Mateos, M. C. Pujol, J. J. Carvajal, M. Aguilo, and F. Diaz, "Passive mode-locking of a Tm-doped bulk laser near $2 \mu \mathrm{m}$ using a carbon nanotube saturable absorber," Optics Express 17, 11007-11012 (2009).

10. A. A. Lagatsky, S. Calvez, J. A. Gupta, V. E. Kisel, N. V. Kuleshov, C. T. A. Brown, M. D. Dawson, and W. Sibbett, "Broadly tunable femtosecond mode-locking in a Tm:KYW laser near $2 \mu \mathrm{m}$," Optics Express 19, 9995-10000 (2011).

11. A. Schmidt, S. Y. Choi, D. I. Yeom, F. Rotermund, X. Mateos, M. Segura, F. Diaz, V. Petrov, and U. Griebner, "Femtosecond Pulses near $2 \mu \mathrm{m}$ from a Tm:KLuW Laser Mode-Locked by a Single-Walled Carbon Nanotube Saturable Absorber," Applied Physics Express 5 (2012).

12. P. Loiko, J. M. Serres, X. Mateos, M. Aguilo, F. Diaz, L. Z. Zhang,

Z. B. Lin, H. F. Lin, G. Zhang, K. Yumashev, V. Petrov, U. Griebner, Y. C.

Wang, S. Y. Choi, F. Rotermund, and W. D. Chen, "Monoclinic $\mathrm{Tm}^{3+}: \mathrm{MgWO}_{4}$ : a promising crystal for continuous-wave and passively $\mathrm{Q}$-switched lasers at $2 \mu \mathrm{m}$," Optics Letters 42, 1177-1180 (2017).

13. P. Loiko, Y. Wang, J. M. Serres, X. Mateos, M. Aguiló, F. Díaz, L. Zhang, Z. Lin, H. Lin, G. Zhang, E. Vilejshikova, E. Dunina, A. Kornienko, L. Fomicheva, V. Petrov, U. Griebner, and W. Chen, "Monoclinic Tm: $\mathrm{MgWO}_{4}$ crystal: Crystal-field analysis, tunable and vibronic laser demonstration," Journal Alloys Compound 763, 581-591 (2018).

14. L. Zhang, H. Lin, G. Zhang, X. Mateos, J. M. Serres, M. Aguiló, F. Díaz, U. Griebner, V. Petrov, Y. Wang, P. Loiko, E. Vilejshikova, K. Yumashev, Z. Lin, and W. Chen, "Crystal growth, optical spectroscopy and laser action of $\mathrm{Tm}^{3+}$-doped monoclinic magnesium tungstate," Optics Express 25, 3682-3693 (2017).

15. J. A. Caird, S. A. Payne, P. R. Staber, A. J. Ramponi, L. L. Chase, and W. F. Krupke, " Quantum electronic-properties of the Na3Ga2Li3F12: $\mathrm{Cr}^{3+}$ laser," IEEE Journal of Quantum Electronic 24, 10771099 (1988).
16. W. B. Cho, J. H. Yim, S. Y. Choi, S. Lee, A. Schmidt, G. Steinmeyer, U. Griebner, V. Petrov, D. I. Yeom, K. Kim, and F. Rotermund, "Boosting the Nonlinear Optical Response of Carbon Nanotube Saturable Absorbers for Broadband Mode-Locking of Bulk Lasers," Advanced Functional Materials 20, 1937-1943 (2010)

17. T. Brabec, C. Spielmann, P. F. Curley, and F. Krausz, "Kerr lens mode locking," Optics Letters 17, 1292-1294 (1992). 